\title{
Barefooted Usability Evaluation: Addressing the Mindset, Resources and Competences*
}

\author{
Anders Bruun \\ Aalborg University, \\ Dept. of Computer Science, \\ Selma Lagerlöfs Vej 300, \\ 9220, Aalborg Ost, Denmark \\ bruunecs.aau.dk
}

\begin{abstract}
Lack of usability specialists, high resource requirements and developer mindsets are three considerable barriers for introducing usability engineering into software companies. This Ph.D. project explores the effect of letting software developers and end users apply usability engineering methods instead of a specialist, a solution which may reduce the barriers.
\end{abstract}

Keywords: Usability evaluation, Training, Software Developers, End Users.

\section{Introduction}

During the last decade software companies have increased their focus on introducing usability engineering into their development processes. However, one challenge experienced by companies is the sheer lack of usability specialists in the industry, which leads to missing competences and ultimately problems of incorporating usability [10]. However, small companies do not even have the privilege of staffing usability specialists as these have to cope with the constraint of low budgets. In practice this means that small software companies do not have the funds to pay for comprehensive consultancy or staffing of usability specialists [7] as they are expensive to hire [9]. Another known problem, denoted the "developer mindset" [1], regards attitudinal aspects such as missing acceptance or low prioritization from the side of the developers. This is also a hindrance to future usability work within a company. Thus, small software companies wanting to focus on usability engineering face these three barriers: Missing competences, high resource demands and developer mindset.

If usability specialists are in scarce supply and small companies cannot afford to hire these, who, then, could undertake the usability work? This project explores the solution of letting the developers themselves and the end users apply usability engineering methods instead of a specialist, which in turn may reduce the three barriers.

* This dissertation work is supervised by Prof. Jan Stage, Department of Computer Science, Aalborg University, Denmark, jans@cs . aau. dk 


\section{Theoretical Foundation and Hypotheses}

Before moving on, the following question should be answered: Why is it that, by letting developers and end users apply usability engineering methods, the barriers of missing competences, high resource demands and the developer mindset will be reduced? To answer this we may turn to Mao Zedongs cultural revolution in China in the 1960's. One vision behind this revolution was to bring better healthcare services to farmers living in rural areas. The problem at the time was the existence of an urban bias of doctors leading to scarce medical competences outside the cities. To counter this problem, Mao transferred medical knowledge from urban doctors to rural areas by letting farmers receive training in basic medicine such as the delivery of babies, how to ensure better sanitation etc. [6]. Thus, some of the farmers would work part time in the rice fields walking around barefooted and part time as doctors in the local area. According to the World Health Organization these so called "barefoot doctors" reduced the amount of resources required, which was observed as reductions in healthcare budgets. These savings were caused by the preventive and tertiary care provided [6]. An additional advantage was that rural farmers perceived the barefoot doctors as peers hereby respecting their advice [11].

Although finding ourselves in a domain differing considerably from Chinese healthcare, we today face a similar challenge as before Mao's Cultural Revolution. Caused by missing competences, high resource requirements and developer mindset, small software companies, in a usability sense, have become the modern rural areas not being able to focus on usability work. This parallel challenge may be met by a parallel solution, i.e. by providing basic training in usability engineering methods, developers and end users could potentially act as barefooted usability personnel. This obviously could reduce the barrier of missing competences and could potentially ease the problem of scarce supply of specialists. Additionally, resource requirements may be brought down as usability engineering is preventive in avoiding expensive projects failures [2] and because the need to employ usability specialists is lessened. Also, other software developers may perceive barefooted usability personnel as peers, hereby accepting the advice given and reducing the barrier of developer mindset.

Thus, based on the notion of barefoot doctors the following hypotheses are derived:

- H1: Barefooted usability engineering reduces the barrier of missing competences.

- H2: Barefooted usability engineering reduces the barrier of resource requirements.

- H3: Barefooted usability engineering reduces the barrier of developer mindset.

\section{Research Questions}

Up until this point the term "usability engineering" has been applied, which covers several methods for analysis, design and evaluation activities. During my Ph.D. I do 
not have time to train developers and end users in all methods, which is why I focus on training these in evaluation methods, and more specifically in conducting user based usability evaluations (as opposed to inspection based). User based evaluations have proven effective in convincing developers of the importance of usability work as they provide first hand insights in difficulties experienced by end users [8] and may, thus, ease the introduction of usability engineering into software companies.

The following two research questions are addressed in the thesis:

- RQ1: What are the previous experiences and future research needs on training developers and end users in conducting usability evaluations?

- RQ2: How do usability evaluations conducted by developers and end users help in reducing the barriers of missing competences, high resource demands and developer mindset? How do developers and end users perform in comparison?

No previous studies have examined how usability evaluations conducted by developers and end users help in reducing all of the three barriers. A recent literature review identifies future research needs regarding training of software developers. The review shows that empirical studies of training developers in user based evaluation methods in general are needed [4].

Additionally, previous studies have shown that evaluations conducted by end users are possible, e.g. by applying remote asynchronous methods without the presence of an evaluator, see e.g. [5]. However, these studies focus on users' performance versus specialists', which leaves room for comparing user performance with that of developers.

\section{Research Method}

In this project my aim is to intervene by training developers and end users in applying usability evaluation methods and to study how these subjects apply methods in a natural setting. These characteristics call for the action case as a research method [3]. To ensure data validity, multiple data collection methods will be employed:

- Observation: E.g. observations on correctness in conducting evaluations, amount of resources required (hours, money etc.) and how usability problems are prioritized and observations on product improvements.

- Surveys and interviews: For instance asking developers and other stakeholders how results from usability evaluations are used, how evaluations should be prioritized, what they perceive as barriers for doing more usability engineering etc.

- Document analysis: Analysis of usability reports with respect to no. of problems identified, quality of problem descriptions, reflections on the usability evaluation procedure etc. 


\section{Research Contribution}

This project will contribute to the HCI research community by providing understanding of the barefooted theory as a driver for reducing the most significant barriers in incorporating usability engineering. This understanding emerges through reference studies in which the theory is applied to create changes in industrial practice. Thus, understanding and change are the types of outcomes this Ph.D. will bring to the research community and industrial practice respectively [3].

\section{References}

1. Bak, J.O., Nguyen, K., Risgaard, P., Stage, J.: Obstacles to usability evaluation in practice: a survey of software development organizations. In: Proc. NordiCHI 2008, pp. 23-32. ACM Press, New York (2008)

2. Bias, R.G., Mayhew, D.J.: Cost-Justifying Usability: An update for the Internet Age. Morgan Kaufmann, San Francisco (2005)

3. Braa, K., Vidgen, R.: Interpretation, intervention, and reduction in the organizational laboratory: a framework for in-context information system research. Accounting, Management and Information Technologies 9(1), 25-47 (1999)

4. Bruun, A.: Training software developers in usability engineering: a literature review. In: Proc. NordiCHI 2010, pp. 82-91. ACM, New York (2010)

5. Castillo, J.C., Hartson, H.R., Hix, D.: Remote usability evaluation: Can users report their own critical incidents? In: Proc. CHI 1998, pp. 253-254. ACM Press, New York (1998)

6. Daqing, Z., Unschuld, P.U.: China's barefoot doctor: Past, present, and future. The Lancet 372(9653), 1865-1867 (2008)

7. Häkli, A.: Introducing user-centered design in a small-size software development organization. Helsinki University of Technology, Helsinki (2005)

8. Høegh, R.T., Nielsen, C.M., Overgaard, M., Pedersen, M.B., Stage, J.: The Impact of Usability Reports and User Test Observations on Developers' Understanding of Usability Data: An Exploratory Study. Int. Journal of Human-Computer Interaction 21(2), 173-196 (2006)

9. Nielsen, J.: Usability inspection methods. In: Proc. CHI 1994, pp. 413-414. ACM Press, New York (1994)

10. Nielsen, J.: Finding usability problems through heuristic evaluation. In: Proc. CHI 1992, pp. 373-380. ACM Press, New York (1992)

11. Markle, W.H., Fisher, M.A., Smego, R.A.: Understanding Global Health. McGraw-Hill, New York (2007)

12. Scholtz, J., Laskowski, S., Downey, L.: Developing usability tools and techniques for designing and testing web sites. In: Proc. Conference on Human-Factors \& the Web (1998) 